\title{
Pathology induced by Pomporhynchus kashmiriensis (Acanthocephala) in the alimentary canal of naturally infected Chirruh snow trout, Schizothorax esocinus (Heckel)
}

\author{
M. IRSHADULLAH ${ }^{1}$, Y. MUSTAFA ${ }^{2}$ \\ ${ }^{1}$ Section of Parasitology, Department of Zoology, Aligarh Muslim University, Aligarh, India, \\ E-mail: malikirshadullah@rediffmail.com; \\ ${ }^{2}$ Section of Parasitology, P. G. Department of Zoology, University of Kashmir, Srinagar
}

\begin{abstract}
Summary
Histopathology of the alimentary canal of Chirruh snowtrout, Scizothorax esocinus (Heckel), naturally infected with the acanthocephalan parasite, Pomphorhynchus kashmiriensis was studied by light microscopy. The proboscis and bulb was found to be deeply penetrated into the host tissues. Macroscopic examination revealed over secretion of mucous and shedding of host tissues at the host parasite interface and white fibrous nodules on the external surface of infected intestine, which was an indication for the presence of parasite. The major changes in parasite induced histopathology were at the site of attachment to the host's intestine which includes destruction of villi and epithelial linings. Increased cellular infiltrations at the site of attachment may be a consequence of host's defence involving cell mediated immunity. In the areas of trunk contact with the host tissue, compression/absence of intestinal folds and loss of columnar appearance of epithelial cells were evident.
\end{abstract}

Keywords: Pomphorhynchus; acanthocephala; histopathology; cellular infiltrations

\section{Introduction}

Fish by virtue of geographical history, ecological situation and physiological specialties harbour many parasitic infections which are considerable threat to the fish industry and act as one of the high risk factor for survival and health of the fishes (Sindermann, 1986). Alimentary canal of fishes is the most favourable environment for establishment and growth of many helminth parasites which often induce morphological changes in the host tissues and thereby causing alteration to the normal intestinal physiology (Castro, 1992; Hoste, 2001). "Pomphorhynchus kashmiriensis described by Kaw (1941)" is the most common acanthocephalan parasite infecting several fresh water fish species in Kashmir valley and uses Amphipod (Gamarus pulex) as intermediate host. The genus Pomphorhynchus has characteristic long hooked proboscis and bulbous neck which were penetrated deep into the gut wall of their piscine host as a result a chain of dynamic interaction takes place at the host parasite interface. Some of the species of Pomphorhynchus perforate the gut and caused damage to the adjoining tissues like liver and pancreas (reviewed by Taraschewski, 2000).

The degree of damage caused by the acanthocephalans to their hosts and intensity of host reactions depends upon depth of parasite penetration within the host tissues and density of worm burdens (Taraschewski, 2000). Many acanthocephalans like, Acanthocephalus anguillae (Taraschewski, 1989a), Pomphorhynchus bulbocoli (Chaicharn \& Bullock, 1967; McDonough \& Gleason, 1981), Pomphorhynchus laevis (Dezfuli, 1991) and Southwellina hispida (Dezfuli et al., 1989) cause extensive damage to the digestive tract because of deeper penetration into the host tissues whereas, Paratenuisentis ambiguus (Taraschewski, 1989b) and Acanthocephalus dirus (McDonough \& Gleason, 1981) comparatively induce less damage due to superficial attachment. In addition to this, the host-parasite interactions in acanthocephalan also depend on the systematic affiliation of the parasites and hosts (Taraschewski, 2000). Numerous reports are available on the harmful effects of many acanthocephalan parasites on the digestive tract and associated organs of different fish species (Esch \& Huffines, 1973; Hine \& Kennedy, 1974; McDonough \& Gleason, 1981; Wanstall et al., 1986; 1988; Dezfuli, et al., 2002a; b; 2008; 2009), but, no information is available due to $P$. kashmiriensis infections in snow trout, Scizothorax esocinus. The present study was therefore undertaken to determine the pathological changes in the intestine of naturally infected $S$. esocinus with $P$. kashmiriensis as well as to establish the host's responses against the parasite, which may be helpful in understanding the host parasite relationship. 


\section{Materials and methods}

Ninety four $S$. esocinus (total length 25 to $40 \mathrm{~cm}$ ) were captured from the Jhelum River Kashmir, India, with the help of local fishermen and brought to the laboratory alive in large water containers. The fishes were kept in well aerated recirculating aquarium, maintained at $10 \pm 2{ }^{\circ} \mathrm{C}$ for several days to remove the undigested food and debris from the gut. The fish were anesthetized with trichloro tertiary - butyl - alcohol and then dissected. The intestines were removed, opened longitudinally and examined for any alterations as well as presence of parasites. In the present study, only heavily infected ( $>50$ worms per intestine) fish intestine with $P$. kashmiriensis were selected for histopathological studies whereas; those having light and/or concurrent infections were rejected and those part of infected intestine were used which, had worm burdens as $8-$ 12 per square $\mathrm{cm}$. Small pieces of both uninfected and infected intestine with attached $P$. kashmiriensis were fixed in Bouin's fixative for $8 \mathrm{~h}$, dehydrated in graded series of ethanol, cleared in xylene and embedded in paraffin wax with a melting point of $58^{\circ} \mathrm{C}$. The specimens were serially sectioned at about $7 \mu \mathrm{m}$ on a rotary microtome, stained with the haematoxylin - eosin and pathological changes were studied under light microscope (Getner, India, GTR 15416).
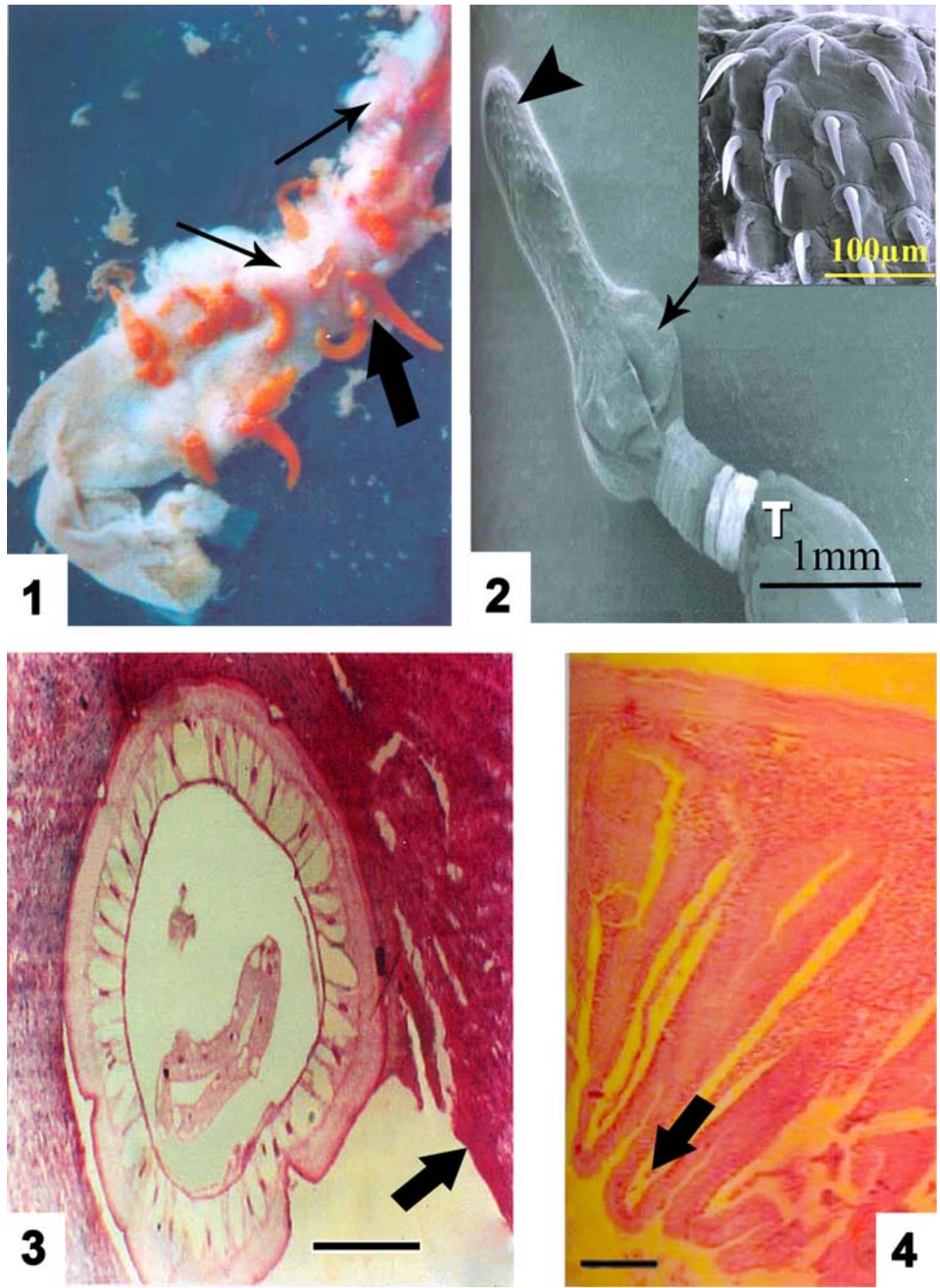

Fig. 1. Infected intestine showing attached P. kashmiriensis (thick arrow), white nodules and shedding of host's tissue (thin arrows) at the site of attachment; Fig. 2. Scanning electron micrograph showing, proboscis (arrow head), bulb (arrow) and trunk (T). Inset: proboscis at higher magnification showing hooks; Fig. 3. Infected intestine showing, deeper penetration of parasite, note the loss of columnar appearance of the epithelial cells near trunk (arrow) (Scale bar $=50 \mu \mathrm{m}$ ); Fig. 4. Uninfected intestine, note the shape and sizes of villi (arrow) 
To study the topography of proboscis, the detached worms were washed with Hanks balanced salt solution, fixed in $4 \%$ buffered glutaraldehyde ( $\mathrm{pH} 7.2)$ at $4{ }^{\circ} \mathrm{C}$ for overnight, washed in $0.1 \mathrm{M}$ cacodylate buffer ( $\mathrm{pH}$ 7.4) and post-fixed in $1 \%$ osmium tetraoxide in Millonig's buffer $(\mathrm{pH} 7.2)$ for $3 \mathrm{~h}$ at $4{ }^{\circ} \mathrm{C}$. After dehydration in graded series of ethanol, specimens were transferred in $100 \%$ acetone, critically dried using liquid $\mathrm{CO}_{2}$, mounted on aluminium stubs and viewed on a Hitachi (S 3000 - H) scanning electron microscope at $5 / 30 \mathrm{KV}$.

\section{Results}

A total of 12 and 16 fishes were found to harbor only Adenoscolex oreini (caryophyllidean cestode) and $P$.

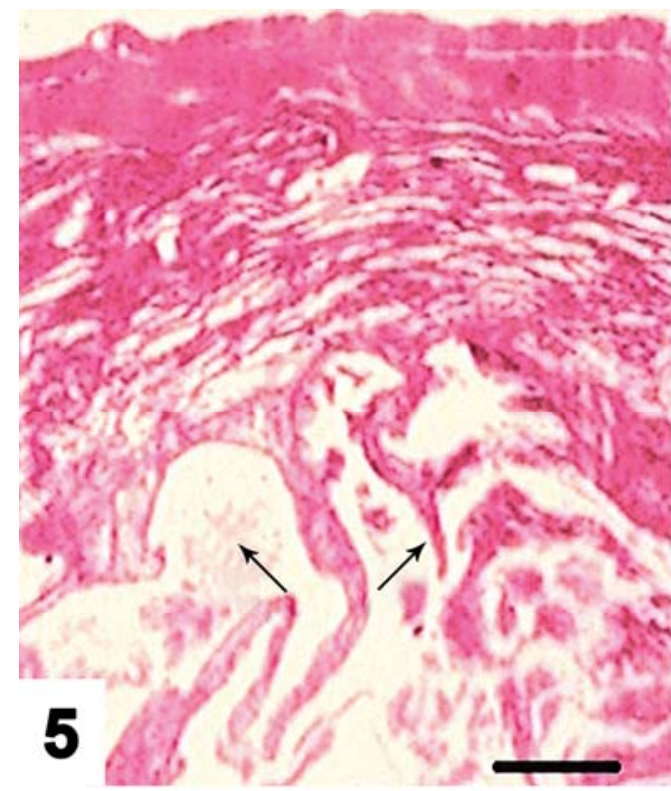

kashmiriensis (acanthocephalan) infection respectively, whereas, 4 fishes were concurrently infected with both the parasites where, the numbers of P. kashmiriensis was always higher than $A$. oreini. Excess secretion of mucous, shedding of host's tissue and yellowish white fibrous nodules was observed macroscopically at the host parasite interface which was more pronounced in heavy infection (Fig. 1). The extension of nodules on the external surface of the infected intestine is an indication for the presence of parasite. In heavy infection, the proboscis of $P$. kashmiriensis was found to perforate the intestine and caused damage to the adjoining tissue of liver and pancreas.

P. kashmiriensis was found to have well developed hooked proboscis and bulb (Fig. 2), by which they were firmly attached with the host intestine. They penetrate their pro-

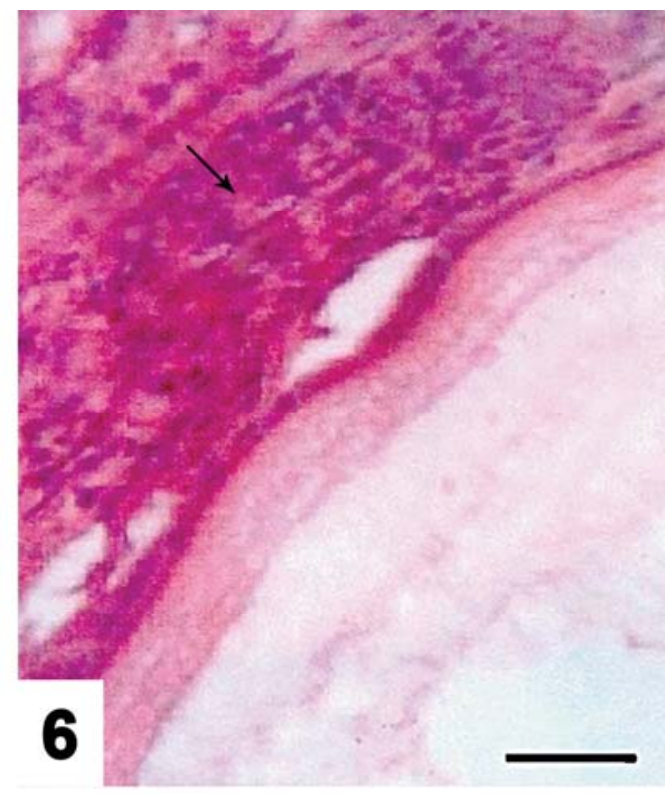

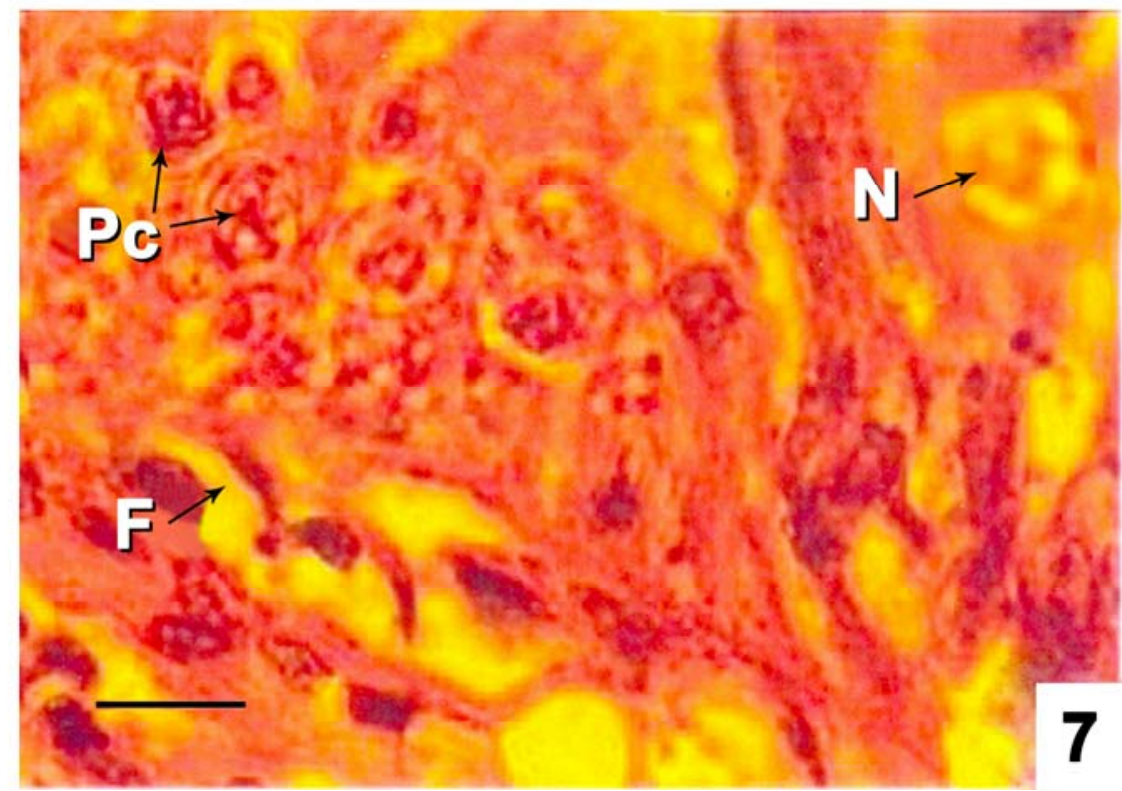

Fig. 5. Infected intestine showing, destruction of villi at the attachment site (arrows) (Scale bars $=50 \mu \mathrm{m}$ ); Fig. 6. Infected intestine showing increased cellular infiltrations at the attachment site (arrow) (Scale bar $=10 \mu \mathrm{m})$; Fig. 7. The infiltrated cells were plasma cells $(\mathrm{Pc})$, neutrophils $(\mathrm{N})$ and fibroblast $(\mathrm{F})(\mathrm{Scal}$ bar $=5 \mu \mathrm{m})$ 
boscis and bulb deep into the host tissues and thereby damage the villi, and epithelial layer (Fig. 3). In the areas of trunk contact with the host tissue, compression/absence of intestinal folds and loss of columnar appearance of epithelial cells were evident. Comparison of the structure between uninfected (Fig. 4) and infected intestine (Fig. 5) revealed the damage of intestinal tissues in infected animals was so severe that it causes total loss of absorptive surface area. Intense cellular infiltrations were noticed at the site of attachment which gave a granuloma like appearance (Fig. 6) and the cells were identified as plasma cells, neutrophils and fibroblasts (Fig. 7).

\section{Discussion}

Generally acanthocephalans cause more damage to the intestinal tissues and induce more complex host response, mainly, due to deeper penetration into the gut mucosa and worm burdens (Bullock, 1963). The pathogenicity caused by acanthocephalans also depends on the parasite/host species and site of localization (Esch \& Huffines, 1973; Hine \& Kennedy, 1974; McDonough \& Gleason, 1981; Hamers et al., 1992). The appearance of yellowish, white fibrous nodules on the external surface of the infected intestine may be due to deeper penetration of proboscis and bulb and can be used as an indicator for the presence of parasite. This finding is similar to those reported by Dezfuli (1991) and Dezfuli et al., (2002b) for P. laevis infection in Leuciscus cephalus. Sometimes, the proboscis of Pomphorhynchus perforates the capsule and penetrates the liver (Chaicharn \& Bullock, 1967; McDonough \& Gleason, 1981; Taraschewski, 1989a). Over secretion of mucous at the host-parasite interface may be a consequence of host reaction for defence, as mucous layer on intestinal mucosa acts as a physical barrier for microorganisms, parasites and their toxins (Lamont, 1992; Bosi et al., 2005) and therefore prevents secondary infection. Excess mucous secretion and significant increase in the number of mucous cell has been reported in the infected fish with acanthocephalans as well as in infected mammals with other parasites, which was correlated with the defence of host (see for references, Bosi et al., 2005). Significant increase in the number of goblet cells has been shown in the parasitized pyloric caeca of green sunfish, Lepomis cyanellus with Leptorhynchoides thecatus, which secrete excessive mucus and provide defence to the host (de Buron \& Nickol, 1994).

The proboscis and bulb of P. kashmiriensis were found to be deeply penetrated till lamina propria and thereby causing erosion of villi and epithelial layer. Similarly, complete penetration of proboscis and bulb and thereby fibrosis, hemorrhage, inflammation and cell necrosis have been reported in infected fishes with several acanthocephalan species (Bullock, 1963; Chaicharn \& Bullock, 1967; McDonough \& Gleason, 1981; Dezfuli, 1991; Taraschewski, 1989a; Wanstall et al., 1986; 1988; Dezfuli et al., 2002b, 2008). The deeper penetration of proboscis and bulb may be assisted by proteolytic enzyme as suggested by Polzar \& Taraschewski (1994) for deeper penetration of $P$. laevis. It was further shown that those acanthocephalan species which, lack the activity of this enzyme cannot penetrate the collagenous structure and takes several days to week to penetrate the intestinal wall (Taraschewski, 1989a). The compression/erosion of epithelial cells in the areas of trunk contact with the host tissues is similar to those reported by Bullock (1963) and Chaicharn \& Bullock, (1967) for Acanthocephalus jacksoni and P. bulbicoli infections respectively. Such damages may adversely affect the digestive and absorptive efficiency of fish intestine by which general health and growth of fish was affected. Alterations in the osmoregulatory process of the host due to such mucosal damage cannot be ruled out and therefore, in future studies this aspect should be taken into consideration.

Intense host reactions and cellular infiltration at the site of P. kashmiriensis attachment was similar to those reported by many workers on other species of Pomphorhynchus (Esch \& Huffines, 1973; Hine \& Kennedy, 1974; McDonough \& Gleason, 1981; Dezfuli, 1991). Chronic inflammation leading to an increased amount of connective tissue, thickening of lamina propria and infiltration of leucocytes has been reported at the site of A. jacksoni attachment (Bullock, 1963). Hamers et al. (1992) reported interspecific differences in the response of leucocytes in infected fish with $P$. ambiguus and suggested that the cellular defence may be involved in determining the host specificity as unsuitable host expel the parasite within a few days.

\section{Acknowledgements}

The authors are grateful to the Chairman, Department of Zoology, Aligarh Muslim University, Aligarh for providing laboratory facilities and to the Dean, Faculty of Life Sciences for financial assistance.

\section{References}

Bosi, G., Arrighi, S., Di Giancamilo, A., Domeneghini, C. (2005): Histochemistry of glycoconjugates in mucous cells of Salmo trutta uninfected and naturally parasitized with intestinal helminths. Dis. Aquat. Org., 64: 45 - 51. DOI: $10.3354 /$ dao064045

BULlOCK, W. L. (1963): Intestinal histology of some salmonid fishes with particular reference to the histopathology of acanthocephalan infections. J. Morphol., 112: 23 44. DOI: $10.1002 /$ jmor. 1051120104

CASTRO, G. A. (1992): Intestinal physiology in the parasitized host: integration, disintegration and reconstruction of systems. Ann. N. Y. Acad. Sci., 664: 369 - 379. DOI: 10.1111/j.1749-6632.1992.tb39775.x

Chaicharn, A., Bullock, W. L. (1967): The histopathology of acanthocephalan infections in Suckers with observations on the intestinal histology of two species of catostomid fishes. Acta Zool., 48: 19 - 42. DOI: 10.1111/j.1463-6395.1967.tb00130.x 
De Buron, I., NickOL, B. B. (1994): Histopathological effects of the acanthocephalan Leptorhynchoides thecatus in the ceca of the green sunfish, Lepomis cyanellus. Trans. Am. Micros. Soc., 13: $161-168$. DOI: 10.2307/3226644 DEZFULI, B. S. (1991): Histopathology in Leuciscus cephalus (Pisces: Cyprinidae) resulting from infection with Pomphorhynchus laevis (Acanthocephala). Parassitologia 33: 137 - 145. PMID: 1844504

Dezfuli, B. S., Capuano, S., Barbieri, C., Volponi, S. (1998): Pathobiology associated with the acanthocephalan Southwellina hispida in the alimentary canal of Phalacrocorax carbo (Aves). In: KANE, A. S., POYNTON, S. L. (Eds), 3rd International Symposium on aquatic animal health. Baltimore, USA, pp. 123.

Dezfuli, B. S., Pironi, F., Giari, L., Domeneghini, C., Bosi, G. (2002a): Effect of Pomphorhynchus laevis (Acanthocephala) on putative neuromodulators in the intestine of naturally infected Salmo trutta. Dis. Aquat. Org., 51: 27 - 35. DOI: 10.3354/dao051027

Dezfuli, B. S., Giari, L., Simoni, E., Bosi, G., Manera, M. (2002b): Histopathology, immunohistochemistry and ultrastructure of the intestine of Leuciscus cephalus (L.) naturally infected with Pomphorhynchus laevis (Acanthocephala). J. Fish Dis., 25: 7 - 14. DOI: 10.1046/j.13652761.2002.00332.x

Dezfuli, B. S., Giovinazzo, G., Lui, A., Giari, L. (2008): Inflammatory response to Dentitruncus truttae (Acanthocephala) in the intestine of brown trout. Fish Shelfish Immunol., 24: 726 - 733. DOI: 10.1016/j.fsi.2007.11.013 Dezfuli, B. S., Lui, A., Giovinazzo, G., Boldrini, P., GIARI, L. (2009): Intestinal inflammatory response of powan Coregonus lavaretus (Pisces) to the presence of acanthocephalan infections. Parasitology, 136: 929 - 937. DOI: 10.1017/S0031182009006295

ESCH, G. W., HUFFINES, W. J. (1973): Histopathology associated with endoparasitic helminths in bass. J. Parasitol., 59: 306 - 313. DOI: 10.2307/3278822

HAMERS, R., LEHMANN, J., STURENBERG, F. J., TARASCHEWSKI, H. (1992): In vitro study of migratory and adherent responses of fish leucocytes to the eel-pathogenic acanthocephalan Paratenuisentis ambiguus (Van Cleave, 1921) Bullock et Sammuel, 1975 (Eoacanthocephala: Tenuisentidae). Fish Shellfish Immunol., 2: 43 - 51. DOI: 10.1016/S1050-4648(06)80026-4

Hine, P. M., KENNEDY, C. R. (1974): Observations on the distribution, specificity and pathogenecity of the acanthocephalan Pomphorhynchus laevis (Müller). J. Fish Biol., 6:521 - 535. DOI: 10.1111/j. 1095-8649.1974.tb04569.x
Hoste, H. (2001): Adaptive physiological processes in the host during gastrointestinal parasitism. Int. J. Parasitol., 31: 231 - 244. DOI: 10.1016/S0020-7519(00)00167-3

KAW, B. L. (1941): Studies on the helminth parasites of Kashmir, Part I. Description of some new species of the genus Pomporhynchus monticelli, 1905. Proc. Ind. Acad. Sci., 13: 369 - 378. DOI: 10.1007/BF03048492

LAMONT, J. T. (1992): Mucus: the front line of intestinal mucosal defense. In: Stead, R. H., Perdue, M. H., CoOK, H., Powell, D. W., BARRETT, K. E. (Eds) Neuro- immunophysiology of the gastrointestinal mucosa: implications for inflammatory disease. Ann. N.Y. Acad. Sci. 664: 190 - 201. DOI: 10.1111/j.1749-6632.1992.tb39760.x

Mcdonough, J., Gleason, L. N. (1981): Histopathology in the rainbow darter, Etheostoma caeruleum, resulting from infections with the Acanthocephalans, Pomphorhynchus bulbocolli and Acanthocephalus dirus. J. Parasitol. 67: 403 - 409. DOI: 10.2307/3280564

Polzar, M., TARASCHEWSKi, H. (1994): Proteolytic enzymes of Pomphorhynchus laevis and in three other acanthocephalan species. J. Parasitol. 80: 45 - 49. DOI: $10.2307 / 3283343$

SINDERMANN, C. J. (1986): Effect of parasite on fish population: practical consideration. In: Howell, M. J. (Ed) Parasitology Quo Vadit? Proceedings of the Sixth International Congress of Parasitology, Australian Academy of Science, Canberra, pp. 371 - 382

TARASCHEWSKI, H. (1989a): Acanthocephalus anguillae in intra -and extraintestinal positions in experimentally infected juveniles of gold fish and carp and in sticklebacks. J. Parasitol. 75: 108 - 118. DOI: 10.2307/3282947

TARASCHEWSKI, H. (1989b). Host- parasite interface of Paratenuisentis ambiguus (Eoacanthocephala) in naturally infected eel and in laboratory infected sticklebacks and juvenile carp and rainbow trout. J. Parasitol. 75: 911 919. DOI: $10.2307 / 3282870$

TARASCHEWSKI, H. (2000). Host-parasite interactions in Acanthocephala: a morphological approach. Adv. Parasitol. 46: 1 - 179. DOI: 10.1016/S0065-308X(00)46008-2

Wanstall, S. T., Robotham, P. W. J., Thomas, J. S. (1986): Pathological changes induced by Pomphorhynchus laevis Müller (Acanthocephala) in the gut of rainbow trout, Salmo gairdneri Richardson. Z. Parasitenkd. 72: 105 114. DOI: $10.1007 /$ BF00927741

Wanstall, S. T., Thomas, J. S., Robotham, P. W. J. (1988). The pathology caused by Pomphorhynchus laevis Müller in the alimentary tract of the stone loach, Noemacheilus barbatulus (L.). J. Fish Dis., 11: 511 - 523. DOI: $10.1111 /$ j.1365-2761.1988.tb00750.x 